\title{
Review of 'Taste Matters: Why We Like the Foods We Do' by John Prescott
}

\author{
Charles Spence
}

\author{
Book details \\ Professor John Prescott \\ Taste Matters: Why We Like the Foods We Do \\ London: Reaktion Books; 2012 \\ 208 pages, ISBN 9781861899149
}

In Taste Matters: Why We Like the Foods We Do, Professor John Prescott - a Sydney-based psychologist, and long-time editor of the popular food science journal Food Quality \& Preference - tackles the fundamental question of why it is that we like certain foods and not others. After all, every one of us has been in the situation where something that we find delicious tastes disgusting to others around us: Japanese natto, or fermented beans, for the westerner, and rice pudding for those from Asia, being but two popular examples. One novel addition to the list of disgusting foods introduced by Prescott in his latest book is the Icelandic dish hakarl, a kind of putrefied shark. This particular fish is somewhat unusual in that it excretes ammonia through its skin. The people from Iceland prepare the shark by burying it in the ground for a couple of months until it reaches maturity. A delicious treat to the locals, apparently, but absolutely horrible to pretty much everyone else. But what exactly are the key factors that are responsible for driving our differing responses to food? And what can we do to change people's food preferences (that is, to get young children to eat more vegetables, say)?

Perhaps just as important as the question of why it is that we do not all like the same foods, however, is the related issue of why it is that we actually do share so many of our food likes/dislikes. Chocolate, for instance, appears to be universally liked. Similarly, most people find the orthonasal smell of coffee to be very pleasing

Correspondence: charles.spence@psy.ox.ac.uk

Crossmodal Research Laboratory, Department of Experimental Psychology, University of Oxford, South Parks Road, Oxford OX1 3UD, England (of course, the same cannot be said for this beverage's bitter taste). As one might expect, answering the question of what factors drive our food likes and dislikes turns out to be a very complex matter. What is more, much of the relevant science has only started to emerge over the last decade or so. That said, Prescott does a great job of guiding the interested reader through the latest research in a style that is both entertaining and highly readable. Should you have come across it, do not pay attention to the reviewer from one of the national newspapers who, in his commentary on Prescott's book, complained that his style was 'biscuity-dry'. It is nothing of the sort; this is the kind of book that one could easily devour in a single sitting.

The focus of Taste Matters is very much on the sensory basis of our food preferences. In the first part of the book, Prescott explains why it is that in matters of taste the type of taste matters. It turns out that we are all born liking sweet tastes; sweetness, after all, normally signifies energy (for example, carbohydrates) in plant matter, exactly what a growing baby needs. Perhaps unsurprisingly, mothers' milk is very sweet. We also seem to be genetically predisposed to like the savoury taste of umami, signalling as it does the presence of protein in a foodstuff. While this fifth taste is very popular in Japanese cuisine, it is much less familiar to westerners. Nevertheless, most people will have come across the distinctive taste in foods such as parmesan cheese and in the meaty taste of tomatoes (perhaps explaining why we label a certain variety as beef tomatoes). In fact, it is the presence of umami that presumably explains why tomatoes are one of the very few fruits (they are classified as such because they contain seeds) that you will virtually 
never find lurking in the bottom of a bowl of fruit salad. Researchers have now shown that newborns also prefer vegetable soups when monosodium glutamate has been added, suggesting to some that such a taste preference may, in fact, be innate.

In contrast to our seemingly innate liking for foods that have a sweet and/or umami taste, at birth we are pretty much indifferent to the taste of salt [1]. It is only at the age of 6 months or so that young infants start to exhibit a preference for solutions that are ever-soslightly salty. As adults, however, we will literally crave salty foods, and the essential minerals that are normally signified by that salty taste when our body needs them. Our ability to detect salty tastes in food is also enhanced when we find ourselves in such a need state. Sourness and carbonation in foods and beverages are very much acquired tastes [2]. These sensory attributes of foods and beverages are not strictly required by our bodies (or by the brains that control those bodies). In our evolutionary past, both sourness and carbonation were probably associated with overripe foodstuffs and hence something to be avoided. Similarly bitterness, the fourth of the socalled basic tastes, is also an acquired taste - with many bitter foods being toxic, and hence being avoided, especially by young children $[3,4]$.

Of course, as adults many of us come to like foods that are sour, bitter, and/or carbonated. In certain cases, we presumably acquire such likes because of the rewards that are associated with their consumption - be it the alcohol in a bitter-tasting pint of beer, or the caffeine in your morning cup of coffee (see for example $[5,6]$ ). The influence of our peers also serves as an effective driver of our food likes and dislikes. Indeed, there are already some innovative interventions being trialled across Europe in this area that appear to be remarkably successful in terms of getting young children to increase their consumption of fresh fruit and vegetables (see $[7,8])$. What is also worth bearing in mind, however, is that some of us are simply inherently more neophilic than others; that is, we are willing, and sometimes actively pursue, novel culinary experiences. It is currently an open question as to whether such individuals may constitute the prime clientele of today's increasingly popular molecular gastronomy restaurants $($ see $[9,10])$. Intriguingly, we learn from Prescott's book that a fear of novel foods (neophobia) can be inherited. The available research suggests that identical twins are more likely to show similar levels of neophobia than are nonidentical twins. By the time we reach adulthood, something like $25 \%$ of us will be classed as moderately to severely neophobic (see [11]).

It is important to realise, however, as Prescott makes absolutely clear, that genetics also plays a crucial role in determining our specific food (and beverage) likes and dislikes. Many of us, somewhere around 25 to $30 \%$ of the population in western countries, are born 'supertasters' - no matter whether we realise it or not [12]. Supertasters may have as many as 16 times more taste buds than other individuals, known as nontasters. (The prevalence of supertasters varies by geographic region: more than $50 \%$ of the population in India, but only 10 to $20 \%$ in Japan and China, have been estimated to qualify as supertasters - see [13].) Supertasters will likely find the taste of Brussels sprouts unacceptably bitter (just as my brother and his two daughters who make an appearance at the start of Chapter 3 of Taste Matters most certainly do). An individual's taster status can be assessed using nothing more complex than a piece of filter paper coated in a bitter-tasting compound such as phenylthiocarbamide or propylthiouracil. Alternatively, however, you can dye a person's tongue blue and then estimate the density of taste buds using a magnifying glass. However, while taste-bud density correlates with one's taster status, it is by no means its sole determinant (see [14]).

While taster status most obviously affects a person's response to certain bitter-tasting foods, it is important to note that it can also impact on our responses to sweetness [15], not to mention alcohol ([16], see also [17]), and the oral-somatosensory textural attributes of foods [18]. It has even been suggested, though not without generating quite a bit of controversy, that nontasters are somewhat more likely to be obese as they are likely to prefer a higher fat content in their salad dressing and in ice cream (see $[12,19])$. Now you might quibble about the name supertaster, as Jeffrey Steingarten, the famous North American food critic (for example, [20,21]), did when he came to visit my laboratory in Oxford. He was very disappointed to be told that he was a nontaster. However, the fact remains that genetics plays a fundamentally important role in determining our food likes and dislikes.

Specific anosmias (that is, an inability to detect certain olfactory stimuli) are also an important part of the story when it comes to the genetics of our food likes and dislikes. It turns out that we are all anosmic to (that is, unable to smell) certain compounds, with certain anosmias simply being much more common than others. One of the most common anosmias results in a small proportion of the population disliking the flavour of cilantro/ coriander. To them, it simply tastes soapy (for example [22]). I myself am completely blind to the distinctive (or so they tell me) smell of 2,4,6-trichloroanisole, which is the damp cellar/wet cardboard smell associated with what is known as 'cork taint' [23]. Not such a bad anosmia to have when you realise that it means I can enjoy all those dusty old bottles of claret they normally bring up from the college cellars in Oxford - wines that, for others, are simply undrinkable. (Estimates vary, but cork 
taint is thought to affect as many as $5 \%$ of all bottles of wine - see [24].) In a very real sense, then, part of the reason why we do not all like the same tastes and flavours originates in the fact that we live in very different taste worlds (see [25]).

Some of the most fascinating research to be reviewed in Taste Matters concerns those findings suggesting that a number of our food likes and dislikes are acquired while we are still in the womb. So, for example, it turns out that neonates whose mothers consumed aniseflavoured foods, or carrot-flavoured milk, during pregnancy are much more likely to appreciate those flavours when born (see [26] for a review). Similarly, in research conducted by Julie Mennella and her colleagues at the Monell Chemical Senses Research Center in Philadelphia, mothers who consumed vegetable juice during the last trimester or while breastfeeding influenced their infants' later preferences once they started to consume solid foods.

Should you have a neophobic child who is no longer breastfeeding, however, do not give up hope. There are still things that can be done to increase the range of foods (and that includes vegetables) your offspring will try. For example, research from Houston-Price and colleagues in Reading demonstrates that merely exposing 2 year olds to pictures of fruit and vegetables increases their willingness to taste those fruits and vegetables [27]. When such results are put together with earlier findings showing that adults like unfamiliar fruit juices more, the more that they have been exposed to them previously [28], the suggestion that emerges is that mere exposure effects (both in the womb, see above, and after birth) can be used to modify a child's liking for various tastes/ flavours (see also [29]). Exposure really can therefore foster liking; and, what is more, if we see someone else eating a novel food, then both children and neophobic adults are more likely to try it.

Ultimately, then, the development of food likes and dislikes reflects the influence of multiple competing factors: genetic inheritance, maternal diet, childrearing practices, learning, cognition, and culture. Prescott does an excellent job of making accessible this large and growing body of evidence concerning what drives our taste/flavour preferences for the lay reader and interested researcher alike. The writing is both entertaining and confident, while the pace is set at just the right level throughout (with any technical language being kept to a minimum). One of the other factors that makes this volume stand out from the increasingly cluttered field of food science and neurogastronomy research are the many anecdotes that pepper the text relating to the role of food, and particularly herbs and spices, not to mention the basic tastes played in driving our history/ exploration in previous centuries (for example [30]). I would certainly recommend this book to anyone wanting to gain a quick and entertaining handle on the fascinating world of taste and flavour. Taste Matters should also be of interest to anyone who has ever stopped to wonder why it is that we do not all like the same foods and/or for those of us who have ever scratched their head trying to figure out what they can do to make their children eat more vegetables.

\section{Competing interests}

The author declares that he has no competing interests.

Received: 15 August 2012 Accepted: 21 August 2012

Published: 1 December 2012

\section{References}

1. Desor JA, Maller O, Andrews K: Ingestive responses of human newborns to salty, sour, and bitter stimuli. J Comp Physiol Psychol 1975, 89:966-970.

2. Chandrashekar J, Yarmolinsky D, von Buchholtz L, Oka Y, Sly W, Ryba NJP, Zuker CS: The taste of carbonation. Science 2009, 326:443-445.

3. Bartoshuk LM, Duffy VB: Chemical senses: taste and smell. In The Taste Culture Reader: Experiencing Food and Drink. Edited by Korsmeyer C. Oxford: Berg; 2005:25-33.

4. Glendinning Jl: Is the bitter rejection response always adaptive? Physio/ Behav 1994, 56:1217-1227.

5. Mobini S, Elliman TD, Yeomans MR: Changes in the pleasantness of caffeine-associated flavours consumed at home. Food Qual Pref 2005, 16:659-666.

6. Zellner DA, Rozin P, Aron M, Kulish C: Conditioned enhancement of humans' liking for flavour by pairing with sweetness. Learning Motivation 1983, 14:338-350.

7. Horne PJ, Hardman CA, Lowe CF, Tapper K, Le Noury J, Madden P, Patel P, Doody M: Increasing parental provision and children's consumption of lunchbox fruit and vegetables in Ireland: The Food Dudes intervention. Eur J Clin Nutr 2009, 63:613-618.

8. Horne PJ, Tapper K, Lowe CF, Hardman CA, Jackson MC, Woolner J: Increasing children's fruit and vegetable consumption: a peer-modelling and rewards-based intervention. Eur J Clin Nutr 2004, 58:1-12.

9. Henriques AS, King SC, Meiselman HL: Consumer segmentation based on food neophobia and its application to product development. Food Qual Pref 2009, 20:83-91.

10. Piqueras-Fiszman B, Spence C: Sensory incongruity in the food and beverage sector: art, science, and commercialization. Petits Propos Culinaires 2012, 95:74-115.

11. Pliner $P$, Hobden K: Development of a scale to measure the trait of food neophobia in humans. Appetite 1992, 19:105-120.

12. Bartoshuk LM: Comparing sensory experiences across individuals: recent psychophysical advances illuminate genetic variation in taste perception. Chem Senses 2000, 25:447-460.

13. Tepper BJ: Nutritional implications of genetic taste variation: the role of PROP sensitivity and other taste phenotypes. Annu Rev Nutr 2008, 28:367-388.

14. Prescott J, Tepper B: (Eds): Genetic Variations in Taste Sensitivity. New York: Marcel Dekker; 2004.

15. Bartoshuk LM: Bitter taste of saccharin related to the genetic ability to taste the bitter substance 6-n-propylthiouracil. Science 1979, 205:934-935.

16. Duffy VB, Peterson JM, Bartoshuk LM: Associations between taste genetics, oral sensation and alcohol intake. Physiol Behav 2004, 82:435-445.

17. Hayes JE, Pickering GJ: Wine expertise predicts taste phenotype. Am J Enol Viticulture 2012, 63:80-84.

18. Eldeghaidy S, Marciani L, McGlone F, Hollowood T, Hort J, Head K, Taylor AJ, Busch J, Stokes JR, Spiller RC, Gowland PA, Francis ST: The cortical response to the oral perception of fat emulsions and the effect of taster status. J Neurophysiol 2011, 105:2572-2581.

19. Gilbertson TA, Liu L, York DA, Bray GA: Dietary fat preferences are inversely correlated with peripheral gustatory fatty acid sensitivity. Ann N Y Acad Sci 1998, 855:165-168.

20. Steingarten J: The Man Who Ate Everything: And Other Gastronomic Feats, Disputes, and Pleasurable Pursuits. London: Headline Publishing; 1998. 
21. Steingarten J: It Must've Been Something / Ate. New York: Knopf; 2002

22. Mauer L, El-Sohemy A: Prevalence of cilantro (Coriandrum sativum) disliking among different ethnocultural groups. Flavour 2012, 1:8.

23. Buser $\mathrm{H}-\mathrm{R}$, Zanier $\mathrm{C}$, Tanner H: Identification of 2,4,6-trichloroanisole as a potent compound causing cork taint in wine. J Agric Food Chem 1982, 30:359-362.

24. Fuller P: Cork taint: closing in on an industry problem. Aust N Z Wine Industry J 1995, 10:58-60.

25. Bartoshuk L: Separate worlds of taste. Psychol Today 1980, 14:48-49. 51 , $54-56,63$.

26. Schaal $B$, Durand $K$ : The role of olfaction in human multisensory development. In Multisensory development. Edited by Bremner AJ, Lewkowicz D, Spence C. Oxford: Oxford University Press; 2012:29-62.

27. Houston-Price C, Burton E, Hickinson R, Inett J, Moore E, Salmon K, Shiba P: Picture book exposure elicits positive visual preferences in toddlers. J Exp Child Psychol 2009, 104:89-104.

28. Pliner $P$ : The effects of mere exposure on liking for edible substances. Appetite 1982, 3:283-290.

29. Harris G: Development of taste and food preferences in children. Curr Opin Clin Nutr Metab Care 2008, 11:315-319.

30. Macinnis P: Bittersweet: The Story of Sugar. Sydney: Allen \& Unwin; 2002.

doi:10.1186/2044-7248-1-23

Cite this article as: Spence: Review of 'Taste Matters: Why We Like the Foods We Do' by John Prescott. Flavour 2012 1:23.

\section{Submit your next manuscript to BioMed Central and take full advantage of:}

- Convenient online submission

- Thorough peer review

- No space constraints or color figure charges

- Immediate publication on acceptance

- Inclusion in PubMed, CAS, Scopus and Google Scholar

- Research which is freely available for redistribution 